\title{
Serum amyloid A levels in acute and chronic urticaria*
}

\author{
Wei Lu ${ }^{1}$, Baobing Chen², Chunfeng Wang ${ }^{1}$, Xiaohong Yang ${ }^{3}$, Changyu Zhou ${ }^{4}$
}

DOI: http:/ / dx.doi.org/10.1590/abd1806-4841.20197761

\begin{abstract}
BACKGROUND: Serum amyloid A is an acute-phase protein. There is no available data regarding serum amyloid A levels in patients with acute (AU) and chronic urticaria (CU).

OвJестіvе: To investigate the association between serum amyloid A and urticaria.

METHODS: This was a case-control study of 81 patients who visited our Hospital between June and December 2016 with a diagnosis of urticaria. Eighty healthy controls (HC) who visited for routine health examination and physical checkups were recruited. Serum amyloid A and C-reactive protein levels were measured by automated methods.

RESULTS: Serum amyloid A and C-reactive protein levels were significantly higher in AU (Serum amyloid A: 207.1 (6.7-439.0) mg/L; C-reactive protein: $16.0(0.2-90.0) \mathrm{mg} / \mathrm{L}$ ) and CU (Serum amyloid A: 6.5 (2.5-35.8) mg/L; C-reactive protein: 1.0 (0.116.0) $\mathrm{mg} / \mathrm{L}$ ) compared with HC (Serum amyloid A: 5.04 (2.0-9.1) mg/L; C-reactive protein: 1.2 (0.1-5.6) mg/L), and in AU compared with CU (all $\mathrm{P}<0.05)$. There were no differences between the CU and HC group. In CU, Serum amyloid A levels in those with moderate/ severe urticaria (median, 16.4 (9.7-35.8) mg/L) were higher than in those with mild urticaria (median, 5.7 (2.5-9.5) $\mathrm{mg} / \mathrm{L}$ ) and HC (all P<0.05). Serum amyloid A and C-reactive protein levels exceeded the normal lab range in 90.7\% and $72.1 \%$ patients with AU compared with $28.9 \%$ and $13.2 \%$ patients with CU, respectively. Significant positive correlations were found between serum amyloid A and C-reactive protein $(r=0.562, \mathrm{P}<0.001)$.
\end{abstract}

STUDY LimitATIONS: There was no comparison between active disease and remission.

CONCLUSION: There was an association between serum amyloid A levels and urticaria. Higher serum amyloid A levels were associated with AU and more severe CU. Serum amyloid A may help to identify CU patients earlier.

Keywords: C-reactive protein; Serum amyloid A protein; Urticaria

\section{INTRODUCTION}

Urticaria is a disease defined by the appearance of pruritic wheals and/or angioedemas. ${ }^{1-3}$ The peak age for onset in adults is between 20 and 40 years. ${ }^{4}$ A population-based questionnaire survey showed that lifetime prevalence rate of urticaria in Germany was $8.8 \%$ among adults. ${ }^{5}$ The disease may cause a decrease in quality of life and may affect academic and professional performance. ${ }^{6}$

Urticaria subtypes can be grouped into acute urticaria (AU) and chronic urticaria (CU) according to the duration and clinical features of the disease. $\mathrm{AU}$ is defined as an event of short duration (less than 6 weeks) and its most common causes include allergic response, infection, and drugs. Some cases may be idiopathic. ${ }^{2,3,7} \mathrm{AU}$ is mostly related to mast cell and basophil activation caused by several triggers, which include IgE mediation, acute viral/bacterial infection, food, and allergic or pseudoallergic reaction to drugs. ${ }^{8}$ Compared to $\mathrm{AU}, \mathrm{CU}$ is characterized by events of continuous activity (more than 6 weeks). ${ }^{2,3,7}$ It is a more complex disease that has several triggering and aggravating factors, ${ }^{9}$ including chronic persistent infections, physical stimuli, drugs, and autoimmune mechanisms.

\footnotetext{
Received 17 October 2017.

Accepted 25 April 2018

Study conducted at the Zhejiang Province Traditional Chinese Medical Hospital, Hangzhou, Zhejiang, China.

Financial Support: The project was funded by the Zhejiang Provincial Administration of Traditional Chinese Medicine (No.2017ZA046). Conflict of Interest: None.

Medical Laboratory Center, Zhejiang Province Traditional Chinese Medical Hospital, Hangzhou, Zhejiang, China. Medical Laboratory Center, The Third People's Hospital of Hangzhou, Hangzhou, Zhejiang, China.

Dermatological Department, Zhejiang Province Traditional Chinese Medical Hospital, Hangzhou, Zhejiang, China.

Radiology Department, Zhejiang Province Traditional Chinese Medical Hospital, Hangzhou, Zhejiang, China.
} 
CU can be identified as an inflammatory disorder of the skin, which is accompanied by an acute phase response (APR). ${ }^{2}$ APR is a local and systemic coordinated reaction to environmental insults that are harmful to the host, including infections, inflammatory processes, and tissue injury. The main biochemical features of APR are numerous changes in the levels of several circulating proteins, including C-reactive protein (CRP), serum amyloid A (SAA), haptoglobin, and fibrinogen. ${ }^{10-12}$

SAA is an acute-phase protein of about $12 \mathrm{kDa}$ in size. SAA is primarily synthesized in the liver by activated monocytes and macrophages and is secreted from certain extrahepatic sites in chronic inflammatory diseases. ${ }^{13}$ Circulatory SAA levels were reported to raise dramatically during acute phase reactions in response to a trauma or infection. ${ }^{8}$ SAA was also shown to exhibit important immunological functions in the process of inflammation. ${ }^{13}$ However, the association between SAA and urticaria (both AU and CU) is unclear.

Therefore, the aim of the present study was to investigate the association between SAA and urticaria. SAA could be used as a disease marker to monitor urticaria.

\section{METHODS}

\section{Study design and patients}

This was a case-control study. We prospectively recruited 81 patients who visited the dermatology clinic of our hospital between June 2016 and December 2016 with a diagnosis of urticaria. AU was defined by lesion recurrence over a period of shorter than 6 weeks. $\mathrm{CU}$ was defined as wheals that had been continuously or intermittently occurring for at least 6 weeks. ${ }^{14}$ The main cause of urticaria in these patients was an allergic reaction such as to medication, insect bites, or food. There were no obvious causes for about half of the cases.

We recruited 80 healthy controls (HC) who visited our hospital for routine health examination and physical checkups. All participants were older than 18 years old.

Exclusion criteria included: 1) patients who have taken antidepressants or oral corticosteroids within 2 months; 2 ) patients who have taken antihistamines within at least 4 days before the study; or 3) skin test or other investigations revealing concomitant diseases. Routine investigations and consultations were performed to exclude infectious diseases. Patients with other chronic skin diseases and those with clinical evidence of urticarial vasculitis or inflammatory state (including rheumatoid arthritis and lupus) were excluded.

The study was approved by the Research Ethics Committee of our hospital. Informed written consent was obtained from all participants.

\section{Urticaria activity}

The urticaria activity score (UAS), defined by the EAACI/ GA $^{2}$ LEN/EDF guideline, ${ }^{2}$ was determined over 4 days and on the day of blood sampling: (no wheals $=0 ; 1-10$ wheals $=1 ; 11-50$ wheals $=2$; and $>50$ wheals $=3$ ) and pruritus intensity ( moderate $=2$; and severe $=3$ ). The UAS scores were determined as daily (minimum $=0$; and maximum $=6$ ) and over 4 days (sum of the daily score values; minimum $=0$; maximum $=24$ ). The UAS was graded as: mild (0-8), moderate (9-16), and severe (17-24).

\section{Blood collection}

All blood samples were obtained between 7 a.m. and 9 a.m. by antecubital puncture. Serum was obtained by centrifugation at $3000 \mathrm{rpm}$ for $5 \mathrm{~min}$. and subsequently stored at $-80^{\circ} \mathrm{C}$ until analysis.

\section{SAA and CRP levels}

SAA levels were measured by latex enhanced immunoturbidimetric method on Architect c16000 platform (Abbott Laboratories, Abbott Park, IL, USA) with a detection limit of $5 \mathrm{mg} / \mathrm{L}$ and a reference range of 0-10 mg/L. Serum CRP levels were measured by immunoturbidimetry, with a detection limit of $0.1 \mathrm{mg} / \mathrm{L}$. Elevated serum CRP was defined as $>5.0 \mathrm{mg} / \mathrm{L}$.

\section{Statistical analysis}

Continuous data was expressed as median and ranges. We used Kruskal-Wallis, Mann-Whitney U, and Student $\mathrm{t}$ tests to screen for differences among the groups, when appropriate. The Pearson correlation coefficient was used to examine the relationships between the variables. Two-sided p-values $<0.05$ were considered statistically significant. All statistical analyses were performed using SPSS 17.0 (IBM, Armonk, NY, USA).

\section{RESULTS}

\section{Clinical characteristics of study participants}

Eighty-one patients participated in this study. Of them, 43 were classified as AU (27 women and 16 men; mean age of 34.7, 1874 years) and 38 as CU (22 women and 16 men; mean age of 42.8, 22-64 years). The HC group consisted of 80 healthy individuals (46 women and 34 men) of comparable age (38.5, 19-74 years) and body mass index (BMI) (Table 1). There were no significant differences in the baseline variables (age, gender, and BMI)

\section{SAA levels in AU and CU patients}

SAA and CRP levels were significantly higher in AU patients (SAA: 207.1 (6.7-439.0) mg/L; CRP: $16.0(0.2-90.0) \mathrm{mg} / \mathrm{L}$ ) than in CU patients (SAA: 6.5 (2.5-35.8) mg/L; CRP: $1.0(0.1-16.0) \mathrm{mg} / \mathrm{L}$ ) and HC (SAA: 5.0 (2.0-9.1) mg/L; CRP: 1.2 (0.1-5.6) mg/L) (all p < 0.05) (Figure 1). There were no differences between the $\mathrm{CU}$ and $\mathrm{HC}$ group.

Among patients with CU, SAA levels in those with moderate/severe UAS (16.4 (9.7-35.8) $\mathrm{mg} / \mathrm{L})$ were higher than in those with mild UAS (5.7 (2.5-9.5) mg/L) and HC (5.0 (2.0-9.1) mg/L) (all $\mathrm{p}<0.05$ ) (Figure 2). There were no differences between patients with mild $\mathrm{CU}$ and $\mathrm{HC}$.

In 39 patients $(90.7 \%)$ with AU and 11 patients $(28.9 \%)$ with $\mathrm{CU}$, SAA concentration exceeded the normal range upper limit value $(0-10 \mathrm{mg} / \mathrm{L})$, and in 31 patients $(72.1 \%)$ with $A U$ and 5 patients $(13.2 \%)$ with $\mathrm{CU}$, the CRP concentration exceeded the normal-range upper limit value $(0-5 \mathrm{mg} / \mathrm{L})$. We observed a significant difference in the proportion of SAA and CRP in patients with AU and $\mathrm{CU},(90.7 \%$ and $28.9 \%, \chi 2=29.99, p<0.001 ; 72.1 \%$ and $13.2 \%$, $\chi 2=26.04, p<0.001$, respectively). (Table 2).

\section{Correlation between SAA and CRP levels}

We found significant positive correlations between SAA and CRP levels $(r=0.562, p<0.0001)$ in patients with urticaria (Figure 3 ).

\section{DISCUSSION}

SAA is an acute-phase protein. Since there is no available data regarding SAA levels in patients with urticaria, the aim of this 
TABLE 1: Baseline demographics and clinical characteristics of patients with urticaria and healthy controls. Eighty-one patients participated in the study. Of them, 43 were classified as AU (27 women and 16 men; mean age of 34.7, 18-74 years) and 38 as CU (22 women and 16 men; mean age of 42.8, 22-64 years). The HC group consisted of 80 healthy individuals (46 women and 34 men) of comparable age (38.5, 19-74 years) and body mass index (BMI). There were no significant differences in the baseline variables (age, gender, and BMI)

\begin{tabular}{|c|c|c|c|c|}
\hline Characteristics & $\mathrm{AU}(\mathrm{n}=43)$ & $\mathrm{CU}(\mathrm{n}=38)$ & $\mathrm{HC}(\mathrm{n}=80)$ & $\mathrm{p}$ \\
\hline Gender, n (\%) & & & & 0.574 \\
\hline Female & $27(62.8)$ & $22(57.9)$ & $46(57.5)$ & \\
\hline Male & $16(37.2)$ & $16(42.1)$ & $34(42.5)$ & \\
\hline Age (years) & $34.7(18-74)$ & $42.8(22-64)$ & 38.5 (19-74) & 0.221 \\
\hline BMI (kg/m2) & $24.0 \pm 3.9$ & $23.6 \pm 4.0$ & $23.9 \pm 3.9$ & 0.3660 \\
\hline \multicolumn{5}{|l|}{ UAS, n (\%) } \\
\hline Mild & & $25(65.8)$ & & -- \\
\hline Moderate/severe & & $13(34.2)$ & & \\
\hline
\end{tabular}

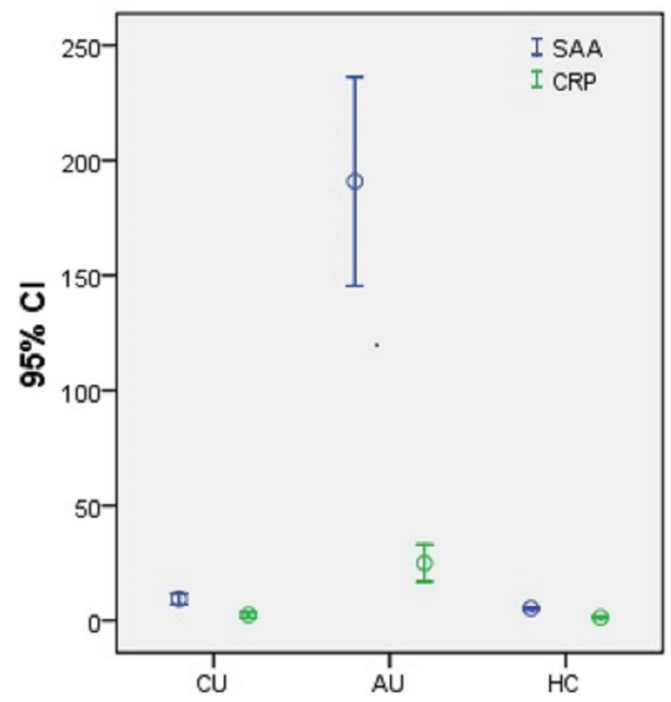

FiguRE 1: Serum amyloid A and C-reactive protein levels in patients with chronic urticaria and acute urticaria and healthy controls. Serum SAA and CRP levels were significantly higher in AU patients (SAA: $207.1(6.7-439.0) \mathrm{mg} / \mathrm{L}$; CRP: $16.0(0.2-90.0) \mathrm{mg} / \mathrm{L})$ when compared with CU patients (SAA: $6.5(2.5-35.8) \mathrm{mg} / \mathrm{L} ; \mathrm{CRP}$ : $1.0(0.1-16.0) \mathrm{mg} / \mathrm{L}$ ) and HC patients (SAA: $5.0(2.0-9.1) \mathrm{mg} / \mathrm{L} ; \mathrm{CRP}$ : $1.2(0.1-5.6) \mathrm{mg} / \mathrm{L})($ all $\mathrm{p}<0.05)$. There were no differences between $\mathrm{CU}$ and $\mathrm{HC}$

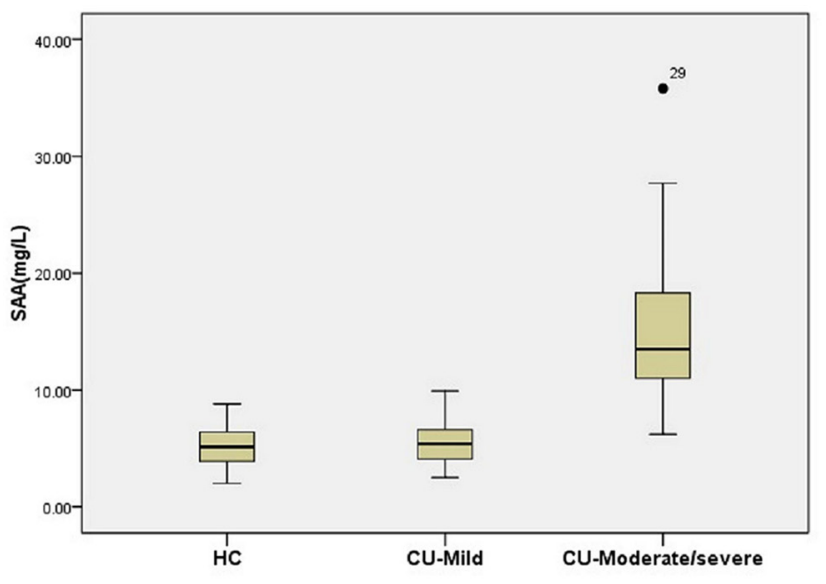

FiguRE 2: Serum amyloid A levels in patients with chronic urticaria and healthy controls according to urticaria severity

TABLE 2: Proportion of patients with SAA and CRP levels exceeding the normal range upper limit value in AU and CU respectively. In 39 patients $(90.7 \%)$ with AU and 11 patients $(28.9 \%)$ with CU, the SAA concentration exceeded the normal range upper limit value (0-10 $\mathrm{mg} / \mathrm{L})$, and in 31 patients $(\mathbf{7 2 . 1} \%$ ) with AU and 5 patients $(13.2 \%)$ with $\mathrm{CU}$, the CRP concentration exceeded the normal-range upper limit value $(0-5 \mathrm{mg} / \mathrm{L})$. We observed a significant difference in the proportion of SAA and CRP in patients with $\mathrm{AU}$ and $\mathrm{CU}(90.7 \%$ and $28.9 \%$, $\chi^{2}=29.99, \mathrm{p}<0.001 ; 72.1 \%$ and $13.2 \%, \chi^{2}=26.04, \mathrm{p}<0.001$, respectively)

\begin{tabular}{cccccc}
\multicolumn{2}{c}{ Cut-off value } & Numbers of AU & Numbers of CU & $\chi 2$ & P \\
\hline & & aboveCut-off & aboveCut-off & & $<0.001$ \\
SAA & $10 \mathrm{mg} / \mathrm{L}$ & $39 / 43(90.7 \%)$ & $11 / 38(28.9 \%)$ & 29.99 & $<0.001$ \\
\hline
\end{tabular}

AU: acute urticaria; CU: chronic urticaria; SAA: serum amyloid A; CRP: C-reactive protein. 


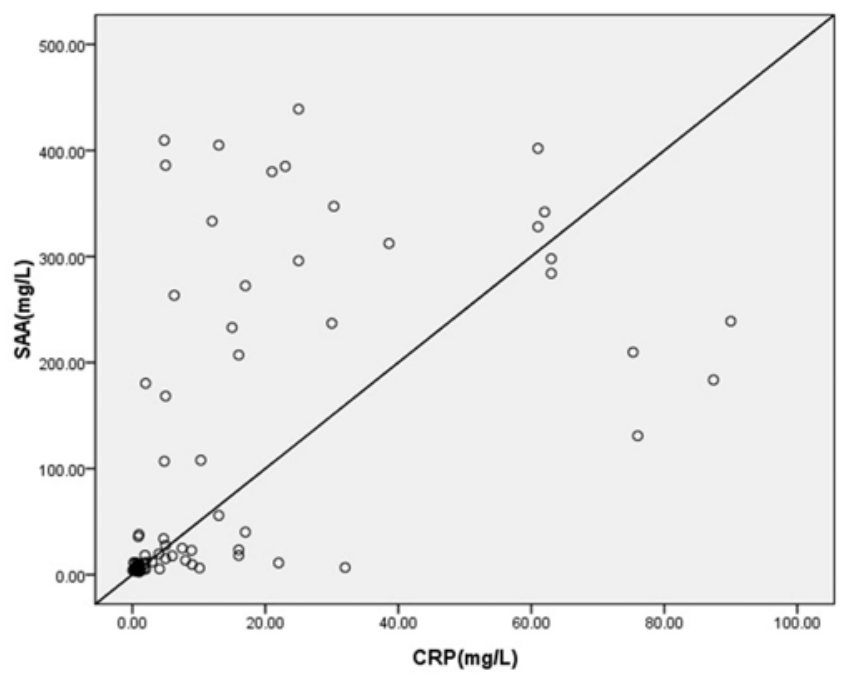

FIGURE 3: SAA levels correlate with CRP. We found significant positive correlations between SAA and CRP levels $(r=0.562, \mathrm{p}<0.0001)$ in patients with urticaria

study was to investigate the association between SAA and urticaria. The results revealed an association between SAA levels and urticaria. Higher SAA levels were associated with AU and more severe CU.

Biological activities of SAA include transport of cholesterol from dying cells to hepatocytes, inhibitory effect on fever, inhibitory effect on the oxidative reaction from neutrophilic granulocytes, inhibitory effect on immune in vitro response, chemotoxic effect on $\mathrm{T}$ cells, monocytes, leukocytes, neutrophils, and mast cells, induction of calcium mobilization by monocytes, and inhibition of platelet activation. ${ }^{15,16}$ Previous studies have indicated that SAA positively correlates with disease activity/severity in ankylosing spondylitis, juvenile idiopathic arthritis, polymyalgia rheumatic, and rheumatoid arthritis. ${ }^{17-20}$

To the best of our knowledge, the present study is the first to show that SAA levels are elevated in patients with urticaria, particularly in patients with AU and moderate/severe CU. Previous studies showed associations between CRP and urticaria, but not SAA. ${ }^{21,22}$ In the present study, SAA and CRP levels were correlated. Both proteins are acute-phase proteins, which supports this correlation..$^{15,23}$
Theoretically, higher SAA concentrations in patients with urticaria could be explained by different mechanisms. It seems likely that similarly to other diseases, associated with the systemic inflammatory response, SAA is primarily synthesized in the liver by activated monocytes and macrophages in response to proinflammatory cytokines. Indeed, acute phase proteins are synthesized by the liver in response to infection, trauma, or inflammation through the action of proinflammatory cytokines such as interleukin (IL)-1, IL-2, and tumor necrosis factor (TNF)- $\alpha .^{15,23}$

Chronic inflammation, perceived as a consecutive series of separate inflammatory stimuli, usually shows increased levels of acute-phase proteins, but these levels are usually lower than the levels observed in acute inflammation. ${ }^{15,24}$ In addition, the response varies among proteins. ${ }^{25}$ In the present study, SAA levels were higher in AU, followed by moderate/severe CU. Patients with mild CU had SAA levels comparable to those of the HC group. In addition, using the actual markers, CU is diagnosed after 6 weeks. SAA concentrations exceeded the normal value in about $90.7 \%$ of patients with AU, which was significantly higher than the $28.9 \%$ value observed in patients with CU. SAA may help in the early detection of CU. This would allow more timely treatments and a better prognosis.

The data indicated viral infections as potential triggers and sometimes as a main causative agent of AU and CU. ${ }^{26}$ SAA is a more sensitive marker than CRP in infections with low inflammatory activity, including many viral infections. ${ }^{27}$ Increased SAA concentrations were observed despite the normal CRP concentrations, accounting for $22.2 \%$ of all patient samples. The findings indicated that SAA was more sensitive than CRP to detect infections with AU and CU. To exclude other pathogenic factors, the increase in SAA concentration alone may suggest a viral infection as the trigger of urticaria.

The present study is not without limitations. There was no comparison between active disease and remission. Although it is known that the levels of acute-phase proteins peak at $24-48 \mathrm{~h}$ after symptom onset, our patients were recruited at different times after the onset of symptoms. ${ }^{15}$ Nevertheless, we were able to detect some significant differences in SAA levels between patients with urticaria and HC.

\section{CONCLUSION}

We observed an association between SAA levels and urticaria. Higher SAA levels were associated with AU and more severe CU. SAA levels may help in the early detection of CU.] 


\section{REFERENCES}

1. Frigas $E$, Park MA. Acute urticaria and angioedema: diagnostic and treatment considerations. Am J Clin Dermatol. 2009;10:239-50.

2. Zuberbier $\mathrm{T}$, Aberer W, Asero R, Bindslev-Jensen C, Brzoza Z, Canonica GW et al. The EAACI/GA(2) LEN/EDF/WAO Guideline for the definition, classification, diagnosis, and management of urticaria: the 2013 revision and update. Allergy. 2014;69:868-87.

3. Bernstein JA, Lang DM, Khan DA, Craig T, Dreyfus D, Hsieh F et al. The diagnosis and management of acute and chronic urticaria: 2014 update. J Allergy Clin Immunol. 2014;133:1270-7.

4. Deacock SJ. An approach to the patient with urticaria. Clin Exp Immunol. 2008;153:151-61.

5. Zuberbier T, Balke M, Worm M, Edenharter G, Maurer M. Epidemiology of urticaria: a representative cross-sectional population survey. Clin Exp Dermatol. 2010;35:869-73.

6. Baiardini I, Pasquali M, Braido F, Fumagalli F, Guerra L, Compalati $E$ et al. A new tool to evaluate the impact of chronic urticaria on quality of life: chronic urticaria quality of life questionnaire (CU-QoL). Allergy. 2005;60:1073-8.

7. Fernando S, Broadfoot A. Chronic urticaria--assessment and treatment. Aust Fam Physician. 2010;39:135-8.

8. Uhlar CM, Whitehead AS. Serum amyloid A, the major vertebrate acute-phase reactant. Eur J Biochem. 1999;265:501-23.

9. Darlenski R, Kazandjieva J, Zuberbier T, Tsankov N. Chronic urticaria as a systemic disease. Clin Dermatol. 2014;32:420-3.

10. Gabay C. Interleukin-6 and chronic inflammation. Arthritis Res Ther. 2006;8(Suppl 2):S3.

11. Gabay C, Kushner I. Acute-phase proteins and other systemic responses to inflammation. N Engl J Med. 1999;340:448-54.

12. Volanakis JE. Human C-reactive protein: expression, structure, and function. Mol Immunol. 2001;38:189-97.

13. Eklund KK, Niemi K, Kovanen PT. Immune functions of serum amyloid A. Crit Rev Immunol. 2012;32:335-48.

14. Zuberbier T, Maurer M. Urticaria: current opinions about etiology, diagnosis and therapy. Acta Derm Venereol. 2007;87:196-205.

15. Lakota K, Mrak-Poljsak K, Rozman B, Sodin-Semrl S. Serum Amyloid $A$ and Its Potential Physiological/Pathological Functions - An Overview of Patents. Recent Pat Endocr Metab Immune Drug Discov. 2010;4:89-99.

16. Jain S, Gautam V, Naseem S. Acute-phase proteins: As diagnostic tool. J Pharm Bioallied Sci. 2011:3:118-27.
17. Jung SY, Park MC, Park YB, Lee SK. Serum amyloid a as a useful indicator of disease activity in patients with ankylosing spondylitis. Yonsei Med J. 2007;48:218-24.

18. Cantarini L, Giani T, Fioravanti A, lacoponi F, Simonini G, Pagnini I, et al. Serum amyloid $A$ circulating levels and disease activity in patients with juvenile idiopathic arthritis. Yonsei Med J. 2012;53:1045-8.

19. Shimojima Y, Matsuda M, Gono T, Ishii W, Ikeda S. Serum amyloid $A$ as a potent therapeutic marker in a refractory patient with polymyalgia rheumatica. Intern Med. 2005;44:1009-12.

20. Connolly M, Rooney PR, McGarry T, Maratha AX, McCormick J, Miggin SM, et al. Acute serum amyloid $A$ is an endogenous TLR2 ligand that mediates inflammatory and angiogenic mechanisms. Ann Rheum Dis. 2016;75:1392-8.

21. Kasperska-Zajac A, Grzanka A, Machura E, Mazur B, Misiolek M, Czecior $\mathrm{E}$, et al. Analysis of procalcitonin and CRP concentrations in serum of patients with chronic spontaneous urticaria. Inflamm Res. 2013;62:309-12.

22. Kasperska-Zajac A, Sztylc J, Machura E, Jop G. Plasma IL-6 concentration correlates with clinical disease activity and serum C-reactive protein concentration in chronic urticaria patients. Clin Exp Allergy. 2011;41:1386-91.

23. Okino AM, Bürger C, Cardoso JR, Lavado EL, Lotufo PA, Campa A The acute-phase proteins serum amyloid $A$ and $C$ reactive protein in transudates and exudates. Mediators Inflamm. 2006:2006:47297.

24. Hedegaard CJ, Lauridsen C, Heegaard PMH. Purified natural pig immunoglobulins can substitute dietary zinc in reducing piglet post weaning diarrhoea. Vet Immunol Immunopathol. 2017;186:9-14.

25. Borek $F$. The acute-phase response to injury and infection. The roles of interleukin 1 and other mediators: Gordon, A.H. and A. Koj (eds.) xxxii +340 pp., illus. Elsevier, Amsterdam, 1985. Dfl.270, ISBN 0-444-80648-2. J Immunol Methods. 1987, 97:147.

26. Imbalzano E, Casciaro M, Quartuccio $\mathrm{S}$, Minciullo PL, Cascio $\mathrm{A}$, Calapai G, et al. Association between urticaria and virus infections: $A$ systematic review. Allergy Asthma Proc. 2016;37:18-22.

27. Lannergård A1, Larsson A, Kragsbjerg P, Friman G. Correlations between serum amyloid $A$ protein and C-reactive protein in infectious diseases. Scand J Clin Lab Invest. 2003;63:267-72.

\footnotetext{
AUTHORS' CONTRIBUTIONS
$\begin{array}{ll}\text { Wei Lu } & \text { (D) ORCID } \\ \text { 0000-0002-5844-4486 }\end{array}$ interpreting the data; Effective participation in research orientation; Critical review of the literature; Critical review of the manuscript.

Baobing Chen $\quad$ (D) ORCID 0000-0001-6149-3636

Statistical analysis; Approval of the final version of the manuscript; Critical review of the manuscript.

Chunfeng Wang $\quad$ (D) ORCID 0000-0003-1087-9285

Approval of the final version of the manuscript; Conception and planning of the study; Critical review of the manuscript.

Xiaohong Yang $\quad$ (D) ORCID 0000-0002-7695-5802

Statistical analysis; Approval of the final version of the manuscript; Effective participation in research orientation.

Changyu Zhou (D) ORCID 0000-0002-6294-6438

Effective participation in research orientation.
}

Statistical analysis; Approval of the final version of the manuscript; Conception and planning of the study; Elaboration and writing of the manuscript; Obtaining, analyzing and

How to cite this article: Lu W, Chen B, Wang C, Yang X, Zhou C. Serum amyloid A levels in acute and chronic urticaria. An Bras Dermatol. 2019;94(4):411-5. 